\title{
Tumor Markers in Clinical and Diagnostic Oncology - Revisited
}

\author{
Sushma Susik MS ${ }^{1}$, Shyam Prasad Reddy $D^{2}$
}

Quick Response Code

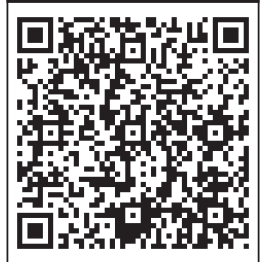

doi: 10.5866/2015.7.10121

'Senior Lecturer,

Department of Oral \& Maxillofacial Pathology

Malla Reddy Dental College for Women,

Suraram, Hyderabad.

${ }^{2}$ Reader,

Department of Oral \& Maxillofacial Pathology

Kamineni Institute of Dental Sciences,

Narketpally, Nalgonda (Dt).

\begin{abstract}
:
The subtle differences between normal and tumor cells are exploited in the detection and treatment of cancer. Some of these differences are designated as tumor markers and can be either qualitative or quantitative in their nature. The structures produced by tumor cells as well as those produced by host tissues in excessive amounts under the influence of tumor cells can function as tumor markers. Speaking in general, the tumor markers are the specific mol ecules appearing in the blood, urine, stool, other bodily fluids or tissues and the occurrence of which is associated with cancer.
\end{abstract}

Most tumor markers are proteins. However, more recently, patterns of gene expression and changes to DNA have also begun to be used as tumor markers. Markers of the latter type are assessed in tumor tissue specifically. Some are associated with only one type of cancer, whereas others are associated with two or more cancer types. There is no "universal" tumor marker that can detect any type of cancer. Sometimes, noncancerous conditions can cause the levels of certain tumor markers to increase. In addition, not everyone with a particular type of cancer will have a higher level of a tumor marker associated with that cancer. Moreover, tumor markers have not been identified for every type of cancer.

Tumor markers are assuming a growing role in all aspects of cancer care, starting from screening to follow-up after treatment, and their judicious application in clinical practice needs a thorough understanding of the basics of pathophysiology, techniques of identification or testing, reasons for out-of-range levels of tumor markers, as well as the knowledge of evidence of their role in any given malignancy. These are, at the most, just an adjunct to diagnosis, and establishing a diagnosis on the basis of tumor markers alone (especially a single result) is fraught with associated pitfalls because of the problem of nonspecificity. The present review focuses on some of the tumor markers in clinical oncology that are often used today.

Key words: Tumor markers, Classification, Applications.

\section{INTRODUCTION}

Tumor markers are substances that are produced by cancer or by other cells of the body in response to cancer or certain benign (noncancerous) conditions. Most tumor markers are made by normal cells as well as by cancer cells; however, they are produced at much higher levels in cancerous conditions. These substances can be found in the blood, urine, stool, tumor tissue, or other tissues or bodily fluids of patients with cancer. Most tumor 
markers are proteins. However, more recently, patterns of gene expression and changes to DNA have also begun to be used as tumor markers. Markers of the latter type are assessed in tumor tissue specifically. ${ }^{1,2}$

More than 20 different tumor markers are in clinical use in oncology. Some are associated with only one type of cancer, whereas others are associated with two or more cancer types. ${ }^{3}$ There is no "universal" tumor marker that can detect any type of cancer and there are some limitations to the use of tumor markers. Sometimes, noncancerous conditions can cause the levels of certain tumor markers to increase. ${ }^{4} \mathrm{I}$ addition, not everyone with a particular type of cancer will have a higher level of a tumor marker associated with that cancer and moreover, tumor markers have not been identified for every type of cancer. ${ }^{5}$

\section{Brief History of Tumor Markers:}

The first known attempt to find tumor markers for malignancy was made 2000 years ago and is described in an Egyptian papyrus where breast cancer was distinguished from mastitis. I ncidentally the first tumor marker in modern medicine was identified by Bence-J ones, who in 1846 detected a heat precipitate in samples of acidified urine from patients suffering from "Mollities osseum". In 1928 W. H. Brown described about ectopic hormone syndrome in a case of pluriglandular syndrome. In 1930 B. Zondek identified HCG (human chorionic gonadotrophin) produced by the trophoblast cells of the fertilised ovum (blastocyst), which is an excellent tumor marker for the monitoring of germ cell tumors. In 1932, ACTH marker was first described by H. Cushing in Cushings' syndrome. In 1949, marker for deletions of blood group antigens was found by K. Oh-Uti in lung cancer patients. ${ }^{3}$

Philadel phia chromosome marker is associated with chronic myeloid leukemia (CML) which was first discovered and described by Peter Nowell in 1960. In 1963, G. I. Abelev demonstrated that transplantable hepatocellular carcinomas of the mouse were synthesizing and secreting into the blood an embryo-specific $\alpha$-globulin subsequently identified as AFP which is an tumor marker in hepatocellular carcinomas. In 1965, Gold et al isolated a glycoprotein molecule from specimens of human colonic cancer and thus discovered the first "tumor antigen," later identified as carcinoembryonic antigen (CEA). Markers for oncogenes were identified by R. Heubner and G. Todaro in
1969. In 1975, Oncogenes probes \& transfection markers were first described by G. Cooper, R. Weinber, M. Bishop in 1980 in human bladder and lung carcinoma cell lines. Suppressor gene marker was first described by H. Harris, R.Sager and A. Knudson in 1985 in Colorectal Tumorigenesis. ${ }^{3}$

Definition of Tumor Marker: There have been numerous attempts to broaden the definition to accommodatethe rapidly expanding set of identified tumor markers and include the following: ${ }^{2}$

1. Substances present in, or produced by, a tumor itself or produced by host in responseto a tumor that can be used to differentiate a tumor from normal tissue or to determine the presence of a tumor based on measurements in blood or secretions.

2. A molecule, a process or a substance that is altered quantitatively or qualitatively in precancerous or cancerous conditions, the alteration being detectable by an assay.

3. Biochemical indicators of the presence of a tumor.

However, in common clinical practice, the term usually refers to a molecule that can be detected in plasma or other body fluids. ${ }^{2}$

\section{Characteristics of Tumor Markers:}

There are three most important characteristics of an ideal tumor marker: ${ }^{2}$

1) It should be highly specific to a given tumor type. (Markers' specificity - Mean probability that a normal tumor marker value derives from a tumor-free individual)

2) It should be highly sensitive to avoid false positive results. (Markers' sensitivity - Mean probability of determining an elevated tumor marker level - over the "cut-off value" - in a tumor-bearing patient)

3) It should provide a lead-time over clinical diagnosis.

Additionally, the levels of the marker should correlatereliably with thetumor burden, accurately reflecting any tumor progression or regression, al ong with a short half-life allowing frequent serial measurements. The test used for detection should be simple, cheap for screening application at mass level and should be of such nature as to be acceptable to the target population. I n reality an ideal tumor marker does not exist. ${ }^{2-4}$ 
As to the literature, an ideal tumor marker should fulfil certain criteria when using it as a test for detection of cancer disease: (1) positive results should occur in the early stages of the disease, (2) positive results should occur only in the patients with a specific type of malignancy, (3) positive results should occur in all patients with the same malignancy, (4) the measured values should correlate with the stage of the disease,(5) the measured values should correlate to the response to treatment, (6) the marker should be easy to measure. Most tumor markers available today meet several, but not all criteria. ${ }^{1}$

\section{Classification of Tumor Markers:}

Tumor markers can be classified in several ways: according to their chemical structure, their tissue of origin, types of malignancies in which they are el evated, etc.

I. In 1995 Waxman J, based on differences in origin, structure, biological function or their relationship to the event in tumor growth or formation, classified tumor markers as follows: ${ }^{6}$

1) Oncofetal antigens e.g. AFP, CEA.

2) Harmones e.g. Catecholamines, Calcitonin, $\beta$ hcg.

3) Glycoprotein's e.g. CA 125, CA 15-3, CA19-9, CA $72-4$, PSA.

4) Metabolites e.g. VMA, HIAA.

5) Tumor associated antigens
a) Viral antigens e.g. Polyoma, SV 40.
b) $\mathrm{MHC}$ related antigens e.g. $\mathrm{H}-2 \mathrm{~K}$ antigen.
c) Enzymes e.g. PAP, NSE, PLAP.
d) Oncogene Products e.g. c-myc, c-erb B2.
e) Cytogenic products e.g. Philadelphia chromosome.

6) Tumor associated markers
a) Proteins e.g. I mmunoglobulin's, $\beta-2 M$. b) Enzymes e.g. Lactate, Dehydrogenase,
Alkaline phosphatase, Pterodines, Pterines.
c) Acute phase proteins e.g. C reactive proteins, Ferritin.
d) Inflammatory markers e.g. ESR, viscosity.

\section{7) Ultrastructural components}

a) Intermediate filament components e.g. Desmin, vimentin
[AFP: Alfa fetoprotein; CEA: Carcinoembryonic antigen; ESR: Erythrocyte sedimentation rate; HIAA: Hydroxy indole acetic acid; NSE: Neuron-specific enolase; PAP: Prostatic acid phosphatase; PLAP: Placental alkaline phosphatase; PSA: Prostate-specific antigen; SV: Simian virus; VMA: Vanillmandelic acid]

II. In 1999, European Group on Tumor markers recommended selected examples of serologic tumor markers and malignant diseases associated with each. Recommendation are as foll ows: ${ }^{7}$

\section{1) Oncofetal Antigens}

a) AFP in Primary HCC and Teratoblastomas of the ovaries \& testis.

b) CEA in Colorectal carcinoma and various carcinomas.

\section{2) Hormones}

a) $\beta$ hcg in Chorio carcinoma and Testicular cancers, trophoblastic tumors.

b) Calcitonin in Medullary carcinoma and Carcinoma of the thyroid, liver cancer, renal cancer.

c) Metanephrines in Pheocytocarcinoma, Neuroblastoma, ganglioneuromas.

d) Chromogranin A in Pheocytocarcinoma, MEN, small cell lung cancer, carcinoid tumors and Neuroblastoma.

e) IGF 1 in Pituitary cancer and Insulinoma.

\section{3) Glycoprotein's}

a) CA 15-3 in Breast cancer and various carcinomas.

b) CA 19-9 in Pancreatic and gastric carcinomas, various carcinomas.

c) CA 72-4 in Gastric carcinomas and various carcinomas.

d) CA 125 in Ovarian carcinoma and various carcinomas.

\section{4) Isoenzymes}

a) PSA in Prostate cancer.

b) NSE in Small cell lung carcinoma and Neuroblastoma, Kidney tumors.

\section{5) Cellular components/products}

a) LASA -P in various carcinomas, leukemia, lymphoma, hodgkins disease. 
b) SCC-A in Squamous carcinoma of the uterus, lung, cervix, head and neck.

c) TAG 2 in Gastric carcinoma and Colorectal, lung, pancreatic and ovarian cancers.

\section{6) Immunoglobulins in}

a) Multiple myeloma in Gammopathies.

[AFP: Alfa fetoprotein; $\beta$-hCG: Beta human chorionic gonadotropin; CA: Carbohydrate antigen; CEA: Carcinoembryonic antigen; HCC: Hepatocellular carcinoma; LASA-P: Lipidassociated sialic acid P; MEN: Multiple endocrine neoplasia; NSE: Neuron-specific enolase; PSA: Prostate-specific antigen; SCCA: Squamous cell carcinoma antigen.]

III. In 2001, J ohnson PJ gave molecular classification of circulating tumor markers which is as follows: ${ }^{8}$

\section{Levels of Classification}

1. DNA
a. Epigenetic - Promoter hyper mythelation. e.g. GSP1, DAP in lung cancer; p15, p216 in liver cancer.
b. Endogenous - Mutations. e.g. NADH dehydrogenase 4.
c. Mitochondrial genetic e.g. (ND4) in urine in bladder cancer.
d. Oncogene -. Mutation. e.g. K-ras in pancreatic cancer, micro satellite alterations in head and neck cancers.
e. Exogenous viral e.g. EBV in NPC and burkitts lymphoma; HPV in cervical cancer.

\section{RNA}
a. Cell based - Tissue specific markers. e.g. PSA m RNA.
b. Endogenous e.g. 20m RNA in breast cancer.
c. Cell free - Circulating m RNA. e.g. tyrosinase m RNA in melanoma.
d. Exogenous viral - Viral RNA. e.g. EBV coded RNA in NPC.

\section{Translational Protein}
a. Native protein e.g. PSA in prostate cancer, CEA in colonic.
b. Conventional markers.
c. Glycon - Aberrant glycosylation. e.g. monosialytactec APF in HCC.

[AFP: Alfa fetoprotein; CEA: Carcinoembryonic antigen; EBV: Epstein-Barr virus; HCC: Hepatocellular carcinoma; HPV: Human papilloma virus; mRNA: Messenger RNA; NPC: Nasopharyngeal carcinoma; PSA: Prostatespecific antigen]

IV. Based upon methods of detection of tumor markers, they are classified into 6 major groups: ${ }^{9-12}$

\section{1) Immunological}
a. Immunohistochemistry
b. Radioimmuno assay
c. Enzyme linked immunosorbent assay

\section{2) Flow cytometry}

\section{3) Cytogenetic analysis}
a. Fluorescent in situ hibridization
b. Spectral karyotying
c. Comparative genomic hybridization

\section{4) Genetic analysis}
a. Sequencing
b. Reverse transcription
c. Gel electrophoresis
d. DNA micro array analysis

5) Proteimics
a. Surface enhanced laser desorption / ionization

V. The most common classification tries to combine their biochemical properties, tissue of origin, and functionality. According to this classification, Srdjan Novakovic in 2004 distinguished tumor markers as follows: ${ }^{1}$

\section{Oncofetal proteins}

\section{Hormones and/or carcinoplacental antigens}

\section{Enzymes}

4. Tumor-associated antigens

5. Special serum proteins

6. Miscellaneous markers

1. Oncofetal proteins:

Oncofetal proteins are antigens that are normally produced during the embryonic development and their production is limited or 
completely absent/stopped in adults. Elevated concentrations in adults result from reactivation of certain genes that control cellular growth and are directly connected to mal ignant process. One of the typical representative of this group is Carcinoembryonic antigen (CEA). ${ }^{1}$

CEA is one of the first known tumor markers. During embryonal development, it is produced in epithelial cells of the gastrointestinal tract, liver, and pancreas. ${ }^{13}$ CEA is important for the follow-up of patients with colorectal cancer because $65 \%$ of all patients (including those with localized disease and stage I cancer), and as much as $100 \%$ of patients with metastatic disease have elevated serum levels of CEA. ${ }^{14}$ Besides, this marker is convenient also for the follow-up of patients with other malignancies especially breast, ovarian, pancreatic, lung, liver, and endometrial cancer. ${ }^{15}$ Serum concentrations between $4-10 \mathrm{ng} / \mathrm{ml}$ can be found either in the patients with malignant or in the patients with benign diseases, and even in some heavy smokers, while concentrations above $10 \mathrm{ng} / \mathrm{ml}$ speak more in favour of a malignancy. Elevated serum concentrations can be found also in the patients with bronchitis, gastritis, duodenal ulcer, liver diseases, pancreatitis, colorectal polyposis, etc. ${ }^{16,17}$ CEA is also the standard marker used to follow patients with col orectal cancer during and after treatment. In this way CEA levels are used to see if the cancer is responding to treatment or if it has recurred after treatment. ${ }^{3,18}$

Alpha-fetoprotein (AFP) is known for approximately as long as CEA. It was discovered in 1963 by G. I. Abelev in the sera of mice with hepatocellular carcinoma. ${ }^{19}$ AFP is a glycoprotein produced in yolk sac, in the epithelial cells of the gastrointestinal tract and liver during embrional development. In pregnancy, AFP enters amniotic fluid through fetal blood, and passes the placenta, thus going into maternal blood. In healthy adults, AFP can be found in the blood in very minute concentrations. ${ }^{20} \mathrm{~N}$ ormal serum concentrations appear approximately 9 months after birth. Elevated serum AFP levels (above $10 \mathrm{ng} / \mathrm{ml}$ ) in adults can be found in the patients with acute viral hepatitis, liver cirrhosis, obstructive icterus, and in some malignant diseases, as pancreatic cancer, lung cancer or gastric cancer. ${ }^{18}$ The main role of AFP is to follow up the patients with hepatocellular carcinoma (95 to $100 \%$ specificity and sensitivity) in whom the concentrations above $1200 \mathrm{ng} / \mathrm{ml}$ practically confirm the diagnosis of primary liver (hepatocellular) cancer, and the patients with non-seminoma germ tumors (specificity $60 \%$ ). ${ }^{21} \mathrm{AFP}$ is al so higher in certain germ cell tumors, such as some testicular cancers, certain rare types of ovarian cancer, and germ cell tumors that start in the chest (mediastinal germ cell tumors). ${ }^{1,3}$

\section{Hormones and/or Carcinoplacental antigens:}

The synthesis and secretion of hormones can sometimes be altered due to malignancies. Quantitative and qualitative alterations of the synthesis and hormone secretion can therefore be the indicators of a malignant process and can be monitored as tumor markers. ${ }^{13}$ Quantitative alterations occur when tumors develop in the tissue of endocrine glands, thus influencing the normal production of hormones by either increasing or decreasing it. This group comprises hormones of malignant endocrine tumors such as parathyroid hormone, insulin, prolactin, catecholamines and others. ${ }^{22,23}$ Qualitative changes take place when malignantly transformed cells of some organs start producing hormones i.e. the so called ectopic hormone production e.g. calcitonin and parathyroid hormone in breast cancer, lipotropin in carcinoid tumors, calcitonin, insulin, parathyroid hormone in thymic malignomas. ${ }^{24}$

Among all hormones, beta human chorionic gonadotropin ( $\beta \mathrm{HCG}$ ) is one of the most applicable tumor markers. $\beta$ HCG is a protein with the molecular mass of $45 \mathrm{KD}$. It belongs to the group of carcinoplacental antigens i.e. proteins that aresynthesized in placenta during pregnancy and can be found in adults only exceptionally. Elevated serum concentrations of $\beta H C G$ can be found in almost all patients (90\%) with germ tumors. $\beta$ HCG has a very short serum half-life (36-48 hours) and is therefore functional to follow up treatment response, as well as to predict prognosis. In combination with AFP, sHCG is an excellent marker for monitoring the patients with germ tumors. ${ }^{18,24}$ 
Calcitonin, a hormone produced by parafollicular $\mathrm{C}$ cells in the thyroid gland, normally helps in regulation of blood calcium levels. Normal calcitonin levels are below 5 to $12 \mathrm{pg} / \mathrm{ml}$ but in medullary thyroid carcinoma (MTC), a rare cancer that starts in the parafollicular C cells, blood levels of this hormone are often greater than $100 \mathrm{pg} / \mathrm{ml}$. This is one of the rare tumor markers that can be used to help detect early cancer. Because MTC is often inherited, blood calcitonin can be measured to detect the cancer in its very earliest stages in family members known to be at risk. ${ }^{1}$

\section{Enzymes:}

Certain enzymes can also be used as tumor markers when they are produced more intensely in malignancies.

Elevated Prostatic acid phosphatise serum concentrations; above $3 \mathrm{ng} / \mathrm{ml}$, can be observed in the patients with prostatic cancer and usually correlate with an advanced phase of the disease when the tumor penetrates the prostatic capsule. The determination of prostatic acid phosphatase is therefore convenient for the discrimination of benign from malignant processes. It was used before the Prostate specific antigen (PSA) test was developed but is seldom used now because the PSA test is better. ${ }^{25}$

Alkaline phosphatise, an iso-enzyme, is synthesized in the liver, bones or placenta. Elevated serum concentrations in patients with malignant disease usually indicate a metastatic spread of the disease into theliver and/or bones, and/or the presence of primary bone tumors such as osteosarcoma. ${ }^{25}$

Chromogranin $A(\mathrm{CgA})$ is made by neuroendocrine tumors that include carcinoid tumors, neuroblastoma, and small cell lung cancer. The blood level of CgA is often elevated in patients with these diseases. It's probably the most sensitive tumor marker for carcinoid tumors. Levels can also be elevated in some advanced forms of prostate cancer that have neuroendocrine features. ${ }^{18}$

Neuron specific enolase (NSE) is a cytoplasmic glycolytic enzyme that was primarily detected in the cells of neuroectodermal origin and in neuronal cells. ${ }^{26}$ The latter were proved to be in the tumor tissue of the tumors with neuroectodermal or neuroendocrine differentiation. ${ }^{27}$ Elevated levels of NSE may also be found in medullary thyroid cancer, melanoma, and pancreatic endocrine tumors. Abnormal levels are usually higher than $9 \mathrm{ug} /$ L. ${ }^{18,28}$

Among other nonspecific markers in this group, lactic dehydrogenase ( $\mathrm{LDH}$ ) is an enzyme that is quite often elevated in the sera of patients with malignant lymphomas and germ tumors (seminomas); elevated ã glutamyl transpeptidase (GGT) indicates cholestasis; and thymidine kinase (TK) helps to evaluate the disease spread in the patients with leukemia, lymphoma, brain tumors, small cell lung cancer, and breast cancer. ${ }^{1}$

\section{Tumor-associated antigens:}

Tumor associated antigens is a heterogeneous group of markers that comprises various membrane structures of tumor cells. Updated technology exploits the possibility of producing specific monoclonal antibodies against certain antigenic structure that is most characteristic for the type of tumor cells. Therefore, the markers in this group are more specific for the type of malignancy than the others and quite often their serum concentrations reflect more accurately the growth or regression of the tumor mass. $^{1}$

Carcinomic antigen 15-3 (CA 15-3) is produced in the secretory epithelium of the breast, lungs, gastrointestinal tract, uterus etc and can be found frequently in the excretions of healthy adults. ${ }^{16}$ Elevated serum concentrations of this marker; above $30 \mathrm{U} / \mathrm{ml}$ are detected predominately in the patients with breast cancer. CA 15-3 is a good indicator of treatment response and disease course in breast cancer patients whose tumors produce that antigen. ${ }^{22}$ The serum level of CA 15-3 can be influenced also by different non-tumoral diseases of the breast, by benign breast tumors, but the values rarely exceed $40 \mathrm{U} / \mathrm{ml}$. Concomitant determination of CA $15-3$ and CEA in breast cancer patients increases the sensitivity, while retaining a substantial specificity of the procedure. $^{18,29}$

Carcinomic antigen 125 (CA 125) is a characteristic marker for ovarian cancer where it is elevated in more than $80 \%$ of patients with 
non-mucinous ovarian cancer. During embrional development, CA 125 is produced in cel omic epithelium, Muellerian ducts, epithelial cells of the pleura, pericardium, and peritoneum..$^{30}$ In adults, CA 125 can be found in mucosa of the cervix uteri and in the lung parenchyma, however, it is not produced by healthy ovarian tissue. ${ }^{31}$ Elevated concentrations of CA 125 (above $35 \mathrm{U} / \mathrm{ml}$ ) can be found not only in the patients with ovarian cancer but also in the patients with benign or malignant gynecological diseases such as endometriosis, ovarian cysts, endometrial cancer, cervical cancer; as well as in the patients with non-gynecological malignancies - lung cancer, prostatic cancer, peritoneal malignant mesothelioma. ${ }^{32}$ In the group of patients with ovarian cancer, CA 125 is most reliable and applicable in the follow-up of patients with epithelial and undifferentiated ovarian cancer. ${ }^{3,} 18$

Carcinomic antigen 19-9 (CA19-9) is a glycolipid and actually represents a modified Lewis's hapten from the blood group system. CA 19-9 is frequently elevated in the serum of patients with gastrointestinal tumors. The marker is slightly more specific for pancreatic and liver cancer. Normal blood levels of CA 19-9 are below $37 \mathrm{U} / \mathrm{ml}$. A high CA 19-9 level in a newly diagnosed patient usually means the disease is advanced..$^{1,4}$

Carcinomic antigen 27-29 (CA 27-29) is another marker that can be used to follow patients with breast cancer during or after treatment. Although it is a newer test than CA 15-3, it's not any better in detecting either early or advanced disease. The normal level is usually less than $40 \mathrm{U} / \mathrm{ml}$. This marker can be elevated in other cancers, too, such as cancers in the colon, stomach, kidney, lung, ovary, pancreas, uterus, and liver. It may also be higher than normal in some non-cancerous conditions, for instance, in women in the first trimester of pregnancy; and in people with endometriosis, ovarian cysts, non-cancerous breast disease, kidney stones, and liver disease. ${ }^{33}$

Prostate specific antigen (PSA) is a serine protease, produced in the prostate tissue and excreted in the prostate fluid where it can have very high concentrations. The role of this serine protease is to prevent coagulation of sperm. ${ }^{25}$
In healthy persons, very minuteamounts of PSA enter the bloodstream so that its concentration in serum is rather low. In the patients with prostatic disease especially in case of prostatic malignancy, the amounts of PSA that enter bloodstream increase significantly, thus generating high serum concentrations. ${ }^{34,} 35 \mathrm{~A}$ blood PSA level below $4 \mathrm{ng} / \mathrm{ml}$ means cancer is unlikely and levels higher than $10 \mathrm{ng} / \mathrm{ml}$ mean cancer is likely. This marker is substantially specific for prostatic cancer and its serum concentrations reflect very well the tumor burden. ${ }^{3,} 18$

$B C R-A B L$ is an abnormal gene seen in chronic myel oid leukemia (CML) cancer cells. PCR can be helpful in detecting this gene in very small amounts in blood or bone marrow. In patient with blood and bone marrow changes that look like those seen with $C M L$, detecting the gene confirms the diagnosis. Also, the level of the gene can be measured and used to guide treatment. ${ }^{18}$

Bladder tumor antigen (BTA) is found in the urine of many patients with bladder cancer. It may be a sign of some noncancerous conditions, too, such as kidney stones or urinary tract infections. The results of the test are reported as either positive (BTA is present) or negative (BTA is not present). ${ }^{1}$

NMP 22 is a protein found in the nucleus of cells. Levels of NMP22 are often el evated (more than $10 \mathrm{U} / \mathrm{ml}$ ) in the urine of people with bladder cancer. It is most often used tolook for recurrent bladder cancer. ${ }^{1}$

BRAF gene defect (mutations) can be found in melanoma, thyroid cancer, and colorectal cancer. About half of melanomas have a BRAF mutation, most often the one called BRAF V600. This mutation causes the gene to make an altered BRAF protein that signals melanoma cells to grow and divide. This mutation can be tested for in tumor tissue. ${ }^{18}$

Solublemesothe in-related pepti des (SMRP) test is sometimes used along with imaging tests to watch a rare type of lung cancer called mesothelioma. It may also be used to see if mesothelioma has recurred after treatment. ${ }^{18}$

\section{Special serum proteins:}

One of the best known of this group is feritin which binds iron intracellularly and is 
responsible for detoxication (e.g. binding of free radicals). Under normal circumstances, high concentrations of feritin can be found in the liver, spleen, and bone marrow. Normal serum level of feritin ranges from 8 to $440 \mathrm{ng} / \mathrm{ml}$. Raised concentrations can be observed in the patients with acute leukemia, lymphomas (especially Hodgkin's lymphomas), lung, liver, and prostatic cancer. ${ }^{13}$

Thyroglobulin is an intracellular glycoprotein responsible for the production and storage of thyroxine. In low concentrations, it can be found in the sera of most healthy persons (0-75 ng/ $\mathrm{ml})$, while extremely high concentrations can be detected in the patients with well differentiated follicular thyroid carcinoma. ${ }^{13}$ Some patient's immune systems make antibodies against thyroglobulin, which can affect test results. Because of this, levels of antithyrogl obulin antibodies are often measured at the same time. ${ }^{18,22}$

Beta-2-microglobul in (B2M) is a protein that is identical with the HLA light chain and thus appears on the cell membrane of almost all differentiated cells. Raised serum concentrations can be observed in the patients with lung, breast, pancreatic, colorectal cancer, as well as lymphomas and chronic lymphoid leukemia (CLL). ${ }^{13}$ Normal levels are usually below $2.5 \mathrm{mg} / \mathrm{L}$. Patients with higher levels of B2M usually have poorer outcomes. B2M is also checked during treatment of multiple myel oma and Waldenstrom macroglobulinemia to see how well the patients are responding to the treatment. ${ }^{22}$

S-100 protein was first isolated from bovine brain. Normal serum concentration of this marker is bel ow $0.3 \mathrm{ng} / \mathrm{ml}$. I $\mathrm{n}$ addition to being a good indicator of traumas to CNS, S-100 can be applied as tumor marker in the patients with neurilemmoma, neurinoma, glioblastoma, astrocytoma, and meningeoma. ${ }^{36}$ It has a special role as prognostic factor and in the follow-up of the patients with malignant melanoma - $\varangle 0.3$ $\mathrm{mg} / \mathrm{ml}-85 \% 3$ years2 survival; $0.3-0.6 \mathrm{mg} / \mathrm{ml}$ $50 \% 3$ years2 survival; >0.6 mg/ml - 10\% 3 years2 survival. Tissue samples of suspected melanomas may be tested for this marker to help in diagnosis. ${ }^{37}$
HER2 (or HER2/ neu, erbB-2, or EGFR2) is a protein that helps some cancer cells to grow. It is present in larger amounts on the surface of breast cancer cells in about 1 out of 5 people with breast cancer. Higher than normal levels can be found in some other cancers, too, such as somestomach and esophageal cancers. HER2 is usually found by testing a sample of the cancer tissue itself, not the blood/serum. Cancers that are HER2-positive tend to grow and spread faster than other cancers. So all newly diagnosed breast cancers and advanced stomach cancers should be tested for HER2. HER2-positive cancers are more likely to respond to drugs that work against the HER2 receptor on cancer cells. ${ }^{18}$

\section{Miscellaneous markers:}

This group of markers correlates perfectly with the changes in vel ocity of cellular proliferation. They are not specific for the type of tumor but generally indicate the presence of a malignant process. The group comprises polyamines, nucleosides and tissue polypeptide antigen (TPA). Polyamines like spermine, spermidine and putrescine were detected in el evated concentrations in urinein cases of a rapid regeneration of cells of certain tissue. Nucleosides, as dimethylguanosine and pseudouridine are components of RNA that enter the circulation in larger amounts in cases of enhanced cellular proliferation. ${ }^{13,} 18$

Tissue polypeptide antigen (TPA) is likewise a nonspecific marker of enhanced cellular proliferation. During embryonal development, it is produced in various embryonal tissues as well as in the placenta. A more rapid cellular proliferation demands a more rapid synthesis of TPA, and consequently, larger amounts of this polypeptide enter the circulation. Therefore, TPA is a common/ universal marker that goes together with pathological cellular proliferation i.e. usually present in malignant transformation regardless of the type or localization of the tissue. Unlike in other markers, the serum concentrations of TPA poorly reflect the tumor burden. Normal serum concentrations of TPA are below $90 \mathrm{U} / \mathrm{ml}$ and concentrations higher than $120 \mathrm{U} / \mathrm{ml}$ can be either a consequence of a malignant or of a benign process. ${ }^{18}$

I mmunogl obulins are not classictumor markers but instead are antibodies, which are blood proteins 
normally made by immune system cells to hel p fight germs. There are many types of immunoglobulins, including I gA, I gD, I gE , I gG, and I gM. Bonemarrow cancers such as multiple myel oma and Waldenstrom macrogl obulinemia often cause a person to have too much of one type of immunoglobulin in the blood. These cancers can also cause pieces of immunoglobulin to be found in the urine. A high level of immunoglobulins may be a sign of one of these diseases. Immunoglobulin levels can also be followed over time to hel p see how well treatment is working. ${ }^{1}$

\section{Application of tumor markers}

Possibilities for the application of tumor markers in oncology are numerous, but the utilization depends upon the sensitivity and specificity of the marker and upon reliability of other methods that are being used for the same purpose. ${ }^{1}$

\section{Utilization of tumor markers in oncology are:}

\section{For Follow-Up of the Disease}

1. Determination in body fluids
a) To monitor the treatment response
b) To detect early the disease recurrence
c) To evaluate the extent of disease
d) To differentiate benign from malignant conditions
e) As screening method for some types of cancer

2. Immunoscintigraphy and Lymphoscintigraphy

3. Immunohistochemistry
a) To set the diagnosis
b) To determine the prognosis
c) To predict the treatment response

\section{For Treatment}

1. Direct cytotoxicity of specific monoclonal antibodies (MoAb)
a) Binding of complement to specific MoAb
b) Binding of cytotoxic cells to specific markers-receptors

2. Binding of drugs to specific MoAb

3. Binding of toxins to specific MOAb

4. Binding of radioactive isotopes to specific MoAb

5. Inhibition of growth factor receptors

\section{Determination of Tumor Markers}

The determination of tumor markers in clinical oncology is hel pful in many processes: in the process of diagnose setting and prognose prediction, in determining the disease extent and planning the treatment, as well as in the early detection of disease recurrence or metastasis. However, the markers in clinical oncology are nowadays, due to their in competences, only exceptional ly appl ied as screening methods for the detection of malignant diseases. Different markers are used for different purposes namely, some of them are more appropriate for the follow-up of the disease and the others for the early detection of the disease recurrence. In addition to theabove applications, tumor markers can also serve as predictors of a disease outcome. The follow up of malignant disease before, during and after treatment, and careful processing of the data, namely, gives us a valuable information about the nature of malignancy, and thus also about the patient's prognosis. In general, extremely high concentrations of tumor markers are predictors of poor outcome. ${ }^{18}$

\section{Determination of tumor marker in patient's sera}

In body fluids, tumor markers are found in low concentrations and for their determination highly sensitive technology is needed. The techniques that are being used are more or less based on the same principle i.e. the determination of antigen-antibody complexes. Most widely used techniques are theradioimmune assay, the enzyme-immune assay, and the luminometric-immune assay, which differ in the compound bound to the detection antibodies, and in the method of detection of the formed complexes. ${ }^{1}$

\section{Factors (in addition to malignant disease) that affect serum concentrations of tumor markers: ${ }^{1}$}

\section{False positive results:}

a) Presence of inflammatory processes;

b) Benign liver diseases and consequential disturbances in metabol ism and excretion (AFP, TPA, CEA, CA 19-9, CA 15-3);

C) Disturbances of renal function (beta-2microglobulin, calcitonin, PSA, CEA, CA 19-9, CA 15-3);

d) Extensive tumor necrosis; as a consequence of diagnostic and therapeutic procedures (digitorectal examination, mamography, surgery, radio and chemotherapy); 
e) As a consequence of different physiological conditions (pregnancy - sHCG, CA 125, CA 153, MCA, AFP, menstrual cycle - CA 125).

\section{False negative results:}

a) Complete absence of production (e.g. CA 19-9 in Le (a-b-) persons);

b) Insufficient expression of a certain antigenic determinant (or production in only some of tumor cells);

c) Insufficient blood circulation in the tumor;

d) Production of immune complexes with autoantibodies;

e) Rapid degradation and clearance of antigens.

\section{Tumor markers are determined:}

1. Prior to surgery or any kind of treatment (chemotherapy, radiotherapy, biological therapy, or hormonal therapy);

2. After the surgery, during the treatment, and after the treatment once in 3 to 6 months 2 period during the first and second year, then once yearly or at regular controls;

3. In case of suspected relapse or disease progression;

4. Prior to introduction of a novel treatment;

5. At least 3 weeks after the introduction of a novel treatment;

6. 2 to 3 weeks after the determination of raised concentrations of the marker.

The proposed concept of tumor marker determinations is applicable in the majority of tumor markers. The above mentioned concept represents only an approximate model that has to be further modified in each patient specifically regarding the fact that each patient is a control to himself (monitoring of the dynamics of serum concentrations). ${ }^{1}$

\section{Drawbacks of tumor markers:}

A simple blood test that could find cancers in their earliest stages could prevent the deaths of millions of people. But very few tumor markers are useful for finding cancer at a very early stage. There are a few reasons/drawbacks for this which are as follows: ${ }^{18}$

1. Almost everyone has a small amount of these markers in their blood, so it's very hard to spot early cancers by using these tests.
2. The levels of these markers tend to get higher than normal only when there's a large amount of cancer present.

3. Some peoplewith cancer never havehigh tumor marker levels.

4. Even when levels of these markers are high, it doesn't always mean cancer is present. For example, the level of the tumor marker CA 125 can be high in women with Gynaecologic conditions other than ovarian cancer.

\section{Conclusion}

Determination of tumor markers for monitoring the course of malignant disease is an established and often an irreplaceable oncological laboratory method. Tumor markers are reliable predominately in monitoring the treatment response, as well as in early detection of disease recurrence; prior to development of clinically notable signs. Due to their incompetence's, tumor markers determinations can be only exceptionally applied as screening methods or as the sole diagnostic tool; however, in combination with other diagnostic methods, they play an important role in the diagnostic process and in treatment planning.

A variety of new tumor markers are in the process of emerging. Indeed, this is a highly studied field in which further improvements in terms of clinical evaluation and treatment of cancers regularly occurs. Current focus is on the use of antibodies to certain epitopes, and a number of antibodies are now being elucidated as potential targeted therapies. Cancer researchers are also now turning to proteomics, which details the study of protein shape, function, and patterns of expression. Proteomic knowledge may serve to screen cancers more efficiently, to find them in early stages as well as to decipher the best treatment options and/or effectiveness of therapy.

\section{References:}

1. Srdjan Novakovic. Tumor markers in clinical Oncology. Radiol Oncol 2004; 38(2): 73-83.

2. S. Sharma. Tumor markers in clinical practice: General principles and guidelines. Indian J Med Paediatr Oncol 2009; 30(1): 1-8.

3. Sheryl Moeller. An underwriters guide to tumor markers. 1993.

4. Tumor markers. National cancer institute at the National Institutes of Health. www.cancer.gov 
5. Shaiquel J, Andrej P, Przemyslaw K, Wojciech Z, J erzy M. A clinical guide to tumor markers categorized under cancer types- A Review. BJ CCSB, 2012; 1: 3-25.

6. Waxman J. Tumor markers. Quart J Med. 1995; 88:233-41.

7. Recommendations of European Group on Tumor Markers (EGTM) Anticancer Res.1999; 19(4): 2791-819.

8. J ohnson PJ . A framework for the molecular classification of circulating tumor markers. Ann N Y Acad Sci. 2001; 945:8-21.

9. Sokoll LJ . Chan DW. Clinical chemistry: Tumor markers. In: Abel off MD, Armitage J O, Niederhuber J E, Kastan MB, McKenna WG, editors. In Abeloff: Clinical Oncology. 3rd ed. Pennsylvania: Elsevier Churchill Livingston; 2004.

10. Schrohl AS, Anderson MH, Sweep F, Schmitt M, Harbeck $\mathrm{N}$, Foekens J, et al. Tumor markers: From laboratory to clinical utility. Mol Cell Proteomics. 2003; 2:378-387.

11. Lindblom A, Liljegren A. Tumor markers in malignancies. Br Med J . 2000; 320:424-427.

12. Cooper DL. Tumor markers. In: goldman, et al., editors. In: Cecil textbook of medicine. 22nd ed. Philadelphia: WB Saunders Company; 2004

13. Rubin $P$, ed. Clinical oncology: A multidisciplinary approach for physicians and students, 7th ed.Philadel phia: W.B. Saunders, 1993: 791.

14. Clinical practice guidelines for the use of tumor markers in breast and colorectal cancer. Adopted on May 17, 1996, by the American Society of Clinical Oncology. J Clin Oncol 1996; 14: 2843-2877.

15. Ballesta AM, Molina R, Filella X, J o J, Gimenez N. Carcinoembryonic antigen in stanging and followup of patients with solid tumors. Tumour Biol 1995; 16: 32-41.

16. J ezersek B, Cervek J, Rudolf Z, Novakovic S. Clinical evaluation of potential usefulness of CEA, CA 15-3, and MCA in follow-up of breast cancer patients. Cancer Lett 1996; 110: 137-144.

17. Fletcher RH. Carcionembryonic antigen. Ann InterMed 1996; 104: 66-74.

18. American cancer society. www.cancer.org

19. Abelev GI. Study of the antigenic structure of tumors. Acta Int Cancer 1963; 19: 80-85.

20. J ohnson PJ . The role of serum al pha-fetoprotein estimation in the diagnosis and management of hepatocellular carcinoma. Clin Liver Dis 2001; 5:145-159.

21. Yuen MF, Cheng CC, Lauder IJ , Lam SK, Ooi CG, Lai CL. Early detection of hepatocellular carcinoma increases the chance of treatment: Hongkong experience. Hepatology 2000; 31: 330-335.

22. Novakovic S. Pregled pomembnejsih tumorskih oznacevalcev v klinicni onkologiji. Ljubljana: Onkoloski institut, 2000: 64.
23. Fowler J E, Platoff GE, Kubrock CA, Stutzman RE. Commercial radioimmuno assay for beta subunit of human chorionic gonadotropin: $\mathrm{F}$ alsely positive determinations due to elevated serum luteinizing hormone. Cancer 1982; 49: 136-139.

24. Bosl GJ , Bajorin DF, Sheinfeld J , Motzer RJ , Chaganti RS Cancer of the testis. In: DeVita VT, Hellman S, Rosenberg SA, eds. Cancer. Principles and Practice of Oncology, 6th ed. Philadelphia: Lippincott, Williams \& Wilkins, 2001: 1491-518.

25. Cooper HC, Robinson MRG, Whelan P, Ferro AM. Tumor markers in prostate cancer. Cancer 1992; 70: 225-229.

26. Schmechel D, Marangos PJ , Zis AP, Brightman M, Goodwin FK. Brain enolase as specific markers of neuronal and glial cells. Science 1978; 199: 313-315.

27. Carney DN, Ihde DC, Cohen MH, Marangos PJ. Serum neuron-specific enolase: a marker for disease extent and response to therapy of small-cell lung cancer. Lancet 1982; I: $583-585$.

28. Wick MR, Brend MD, Scheithauer W, Kovacs K. Neuron specific enolase in neuroendocrine tumors of the thymus, bronchia and skin. Am J Pathol 1983; 79: 703-707.

29. Geraghty J G, Coveney CE, Sherry F, O'Higgins J N, Duffy M. CA 15-3 in patients with locoregional and metastatic breast carcinoma. Cancer 1992; 70:2831-2834.

30. Tuxen MK, Sol etormos G, Dombernowsky P.Tumor markers in the management of patients with ovarian cancer. Cancer Treat Rev 1995; 21:215-245.

31. Novakovic S, Sersa G, Krosl G, Plesnicar S. CEA, MCA and CA 125 tumor markers in pregnant women. Radiol Iugosl 1990; 24: 79-84.

32. J acobs IJ, Skates SJ, MacDonald N, Menon U, Rosenthal AN, Davies AP, et al. Screening for ovarian cancer: A pilot randomized controlled trial. Lancet 1999; 353: 1207-1210.

33. Steinberg $W$. The clinical utility of the CA 19-9 tumorassociated antigen. Am J Gastroenterol 1990; 85: 350-355.

34. Woodrum LD, Brawer KM, Partin WA, Catalona J W, Southwick CP. Interpretation of free prostate specific antigen clinical research studies for the detection of prostate cancer. J Urol 1998; 159: 5-12.

35. Catalona WJ , Partin AW, Slawin KM, Brawer MK, Flanigan RC, Patel A, et al. Use of the percentage of free prostate specific antigen to enhance differentiation of prostate cancer from benign prostatic disease: A prospective multicenter clinical trial. J AMA 1998; 279: 1542-1547.

36. Ghanem G, Loir B, Morandini R, Sales F, Lienard D, Eggermont $A$, Lejeune $F$. On the release and half-life of S100B protein in the peripheral blood of melanoma patients. Int J Cancer 2001; 94: 586-590.

37. J ury SC, McAllister J E, MacKie MR. Rising levels of serum S100 protein procedure other evidence of disease progression in patients with malignant melanoma. Br J Derm 2000; 143: 269-274. 